\title{
Retrograde transport- the journey back to Golgi
}

\author{
Avik Banerjee \\ Department of Plant Sciences, Bose institute, Kolkata, India
}

\begin{abstract}
Some proteins like acid hydrolase receptor, hetero trimeric G protein, EGFR, processing peptidase as well as toxin like Shiga toxin, ricin and lipid trafficks through various intermediate stations while travelling from endosomes to trans Golgi network/Golgi ie 'Retrograde' transport after being internalised. Here the critical molecular events in the retrograde pathway along with the factors involved are summarised. Then the importance and implication in various cellular processes are discussed. Lastly, I conclude about the future perspective and in what way we can exploit the process for applied research.
\end{abstract}

Keywords: Clathrin, Early endosome, Late endosome, Retromer, Shiga toxin, trans-Golgi network (TGN)

\section{Introduction}

Proteins and lipids gets transported to the plasma membrane from endoplasmic reticulum during exocytosis and replenished by the retrograde trafficking pathway back to trans Golgi network (TGN) and golgi while travelling through different endosomes (late, early, recycling) ie transport intermediates Fig. 1. Retrograde transport is a part of a elaborate and complex process - endocytosis, at plasma membrane that affects many cellular process like signalling, nutrient uptake, development, sensory neuron pathways etc. Some of the mechanisms that underlie the endocytic process like clathrin dependent (transferring receptor), clathrin independent internalisation (bacterial shiga toxin), receptor recycling have been being studied in great detail $[1,2,3]$. But the mechanism of endosomal trafficking of membranes through the retrograde route has garnered interest lately. While studying plant toxin ricin and tracking its localisation led to discovery of retrograde pathway. Ricin interferes with protein synthesis by modifying ribosomal RNA and was located to be present in golgi membranes of target cells[4,5].The most convincing model of endosome-TGN interface was put forward by the path of mannose 6-posphate receptor(MPR) recycling. MPRs are one of the best researched cargo proteins that revealed the trafficking, sorting process involved while transporting precursor lysosomal hydrolases to lysosomes. MPRs recognise the unique post translational modification ie mannose 6-P residue, carried out at golgi to the precursor hydrolases. MPRs carry the cargo from TGN and release the enzyme in the late endosomal lumen under low $\mathrm{pH}$ where enzyme gets cleaved proteolytically to become active and MPR shuttles back to TGN without itself being degraded to start another cycle, an amazing journey through intermediate stations[6,7]. The pathway was further characterised while studying the molecules that exploit it eg. various toxins eg- cholera, Pseudomonas exotoxin A, shiga and pertussis. In this review I will be providing a brief account about the molecular events of the pathway.

\subsection{Cargo sorting and budding}

\section{Critical Aspects Of The Pathway}

While studying a sorting receptor protein in budding yeast S.cerevisiae (this organism has contributed a great deal in retrograde research) Vps 10 which binds to sorting signals of newly synthesized proteins and itself gets transported back from endosomes to TGN led to discovery of 'retromer'. A conserved protein sorting complex present at the endosome that directs cargo in the retrograde route [8,9]. Retromer coat protein complex is a hetero pentamer consisting of a trimer Vps26-Vps35-Vps29 and a sorting nexin (SNX) dimer. In yeast sorting nexins consist of Vps17and Vps5 whereas in human they are SNX 1,2,5,6. The SNX dimer binds in different combination with trimer Vps26-Vps35-29 [10,11]. The Vps10 family like sortilin, sorLA has been studied to elucidate the trafficking route from TGN-Golgi interface, which further revealed the role of Vps 10 in endocytosis and intracellular signalling. SNX ha sspecialised domains for sorting functions, a BAR (Bin/Amphiphysin/Rvs) domain that detects and induce curvature and Phox (PX) domain which interacts with endosomal Phosphoinositides that aid in retrograde trafficking. Vps 26-Vps35-Vps29 is called the membrane recognition complex as it binds to cytosolic residues of receptor cargo like sortilin and MPR. The SNX drive tubule formation from endosomal membranes and cargo recognition complex recruits cargo into these tubules as the retromer complex decorates the tubulo- vesicular structure as a coat [12].

A variety of sorting signal has been identified that leads to directional trafficking eg MPRs exhibit sorting signal in its cytoplasmic domain, a phenylalanine-tryptophan motif which Tail interacting protein of $47 \mathrm{KDa}$ (TIP47) recognises and as as suggested is responsible for its late endosome-TGN travel and prevents 
MPRs degradation in lysosome [13]. Rab9 is also argued that it binds to TIP47 to enhance its affinity towards MPR.

Another important protein that has been strongly argued to be functionally associated with retromer is 'clathrin' in sorting and budding process apart from its role as a coat protein. Shiga toxin gets blocked along with transferrin receptors in lumen of endosomes in clathrin depleted cells unlike in the TGN/Golgi as in control conditions. Further Shiga toxin accumulate in membrane tubules of transferrin receptor positive endosomes of Vps35 or 26 depleted cell. This proves the close link of clathrin and retromer, where various clathrin adaptors has supporting role to play as well like AP1 and epsinR recruited by PtdIns(4)P lipids [14,15].

\subsection{Docking and fusion}

Tethering is process of capturing transport intermediates to their respective target membranes where 'docking'/landing happens and finally fusion. Tethering proteins like golgin-97 and golgin-245 through their GRIP domains by Arl1 GTPases link retrograde intermediates with TGN as an initial step for trafficking of shiga toxin [16]. Eventually the fusion with golgi membranes ie target organelle is carried out by the (SNARES) $\mathrm{N}$-ethyl maleimide-sensitive fusion factor attachment receptor. The fusion of intermediate carriers of retrograde route to organelle happens due to interaction of v-SNARES on the retrograde carriers and t-SNARES on the TGN aided by GTPases of ADP ribosylation factors (Arf) family. This attachment and formation of SNARE complex leads to fusion of membranes and delivery of retrograde cargo. Tethering, docking and fusion process is aided by many regulatory factors like Rabs eg., GCC185, a tethering factor interacts with Rab9 (a GTPase in late endosome-TGN trafficking of MPR)as well as with Rab6 and syntaxin11(regulate early endosome-TGN traffic). Tethering and fusion factors differ based on cargo and membrane interfaces. Eg, SNARE complex associate with syntaxin 5 and syntaxin 6/16 to help fusion while retrograde transport of shiga toxin from early endosome and SNARE complexes with syntaxin 10 during trafficking of MPR from late endosome-TGN $[17,18]$.

\subsection{Physiological}

\section{Role Of Retrograde Transport}

In adipocytes and skeletal muscles major glucose transporter, GLUT4 is sequestered in storage compartments in resting state. While exocytosis, due to insulin activation GLUT4 is recruited to plasma membrane of cell then as stimulation subsides it gets sorted and takes the retrograde route through recycling endosome to TGN and regrouped in storage compartments. Effecient sorting in the retrograde pathway is crucial for maintainance of glucose homeostatsis through recycle and reassembly [19,20]. Similarly when there is low extra cellular copper concentration menkes proteins (member of copper transport pathway) retrieval from plasma membrane to TGN through retromer is faster than exit from TGN, thus accumulation of menkes protein occur in TGN. When concentration increases so does distribution of menkes protein on plasma membrane, thus retrograde sorting ensures the copper utilisation efficiency in the cell [21]. In case of polarised cell secretion retrograde path helps to maintain a steady pool of cargo ie matrix type metallo proteases (MMTPs) in the TGN after being internalised and recycled back [22], so that the proteases can be secreted when in need to cleave extra cellular matrix during angiogenesis, tissue reorganisation.

\subsection{Developmental}

Wnt proteins are signalling molecules secreted by cell to maintain intercellular cross talk that has role in position determination, cell fate and survival decisions while development into multicellular organism. This crucial highly conserved family of factors undergoes post translational modification like glycosylation, lipidification while present in early secretory vesicles on their way to secretion from golgi. Due to these modification Wnt secretion requires the integral membrane receptor protein Wntless, which resides predominantly in golgi and trafficks between that and plasma membrane. Wnt signalling gets affected in D.melangaster and C.elegans when mutation occur in retromer subunits. Further studies revealed that Wls binds with Wnt in golgi and acts as sorting receptor,WIs travels to plasma membrane and helps release of Wnt. Then Wls gets internalised and trafficks back to TGN by retromer mediated sorting ensuring the sustainance of Wnt signalling. Thus the Wls amount in TGN imparts a regulatory role on Wnt signal level through retromer, and when retromer function is impaired it adversely affects the Wls stabiltity, hence the Wnt secretion process [23].

\section{Applications Of The Pathway}

As previously mentioned, while studying how the toxins and virus gets entry into the cell and traffic through various stations to reach cellular targets to cause cellular malfunction, led to exciting discoveries about the retrograde molecular mechanism, trafficking factors, retromer sorting, regulators etc. But scientists are reaping the benefit of toxin entry into therapeutic use. Eg Specific antigens can be attached to shiga toxin which selectively targets the dendritic cell that expresses GB3 receptor. Receptor with antigen translocates to cytosol 
through retrograde route [24] and induces MHC class I antigen presentation as a result. This delivery system has been utilised in cancer models as well when exogenous antigens coupled to shiga toxin targets dendritic cell in mice to cure tumour growth due to induction of cytotoxic T lymphocytes [25]. This efficient mode of drug delivery is gaining immense importance due to its specificity, ability of the carriers which are part of retrograde machinery not to be degraded and this system enables the exogenous antigen to get into active form as they interact with the target cell for prolonged period while trafficking, hence augments the efficacy.

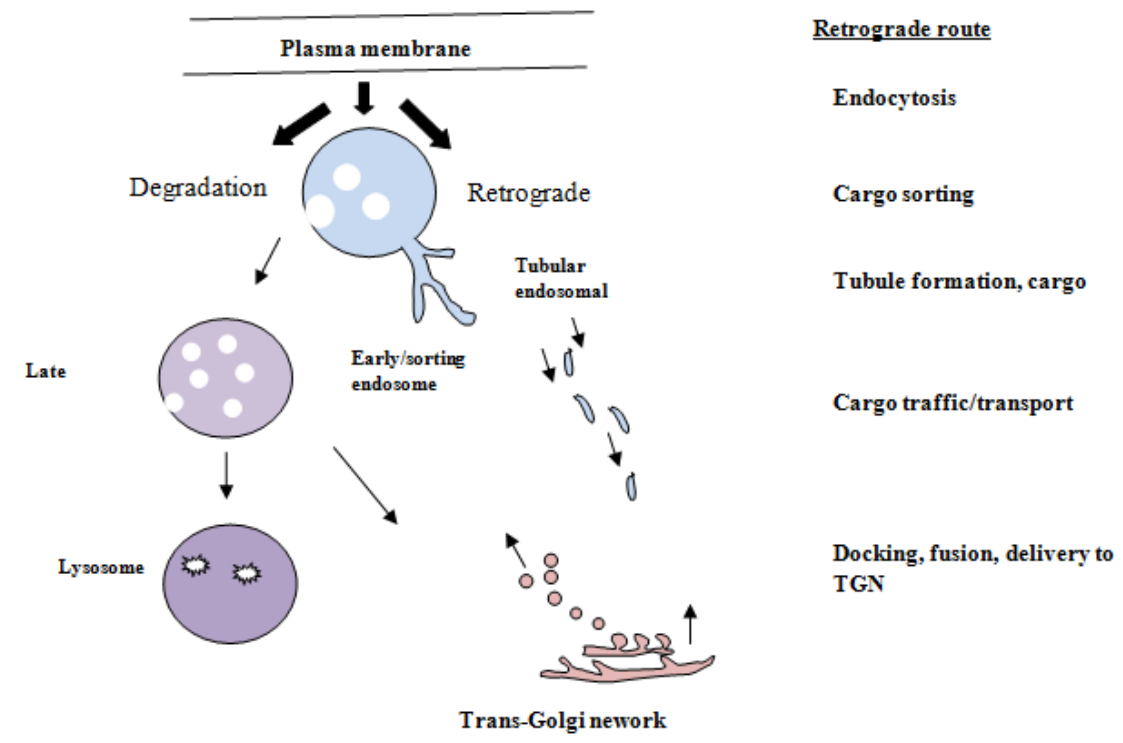

Fig 1- Retrograde transport route from plasma membrane to golgi/TGN- a model

TABLE 1 - Implication of Retrograde transport in disease [26, 27]

\begin{tabular}{|c|c|c|c|c|}
\hline \multirow[t]{3}{*}{ Cargo } & $\begin{array}{l}\text { Protein } \\
\text { name }\end{array}$ & class & Disease & $\begin{array}{l}\text { Retrograde machinery } \\
\text { used }\end{array}$ \\
\hline & $\begin{array}{l}\text { Amyloid } \\
\text { precursor } \\
\text { protein } \\
\text { APP }\end{array}$ & $\begin{array}{l}\text { Type I integral } \\
\text { membrane } \\
\text { protein }\end{array}$ & $\begin{array}{l}\text { Proteolytic prodect } A \beta \text { is } \\
\text { linked to } \\
\text { Alzheimer's disease }\end{array}$ & SorLA, retromer, SNX17 \\
\hline & $\begin{array}{l}\beta \text { site } \\
\text { APP } \\
\text { cleavage } \\
\text { enzyme }\end{array}$ & Protease & $\begin{array}{l}\text { APP processing, Alzheimer's } \\
\text { disease }\end{array}$ & Retromer, GGA \\
\hline \multirow{4}{*}{$\begin{array}{l}\text { Sorting } \\
\text { factors }\end{array}$} & $\begin{array}{l}\text { HIV1 } \\
\text { envelop }\end{array}$ & Coat protein & Viral assembly and infection & $\begin{array}{l}\text { Retromer, trafficking } \\
\text { factors }\end{array}$ \\
\hline & $\begin{array}{l}\text { HIV1 } \\
\text { nef }\end{array}$ & $\begin{array}{l}\text { Transmembrane } \\
\text { connector }\end{array}$ & $\begin{array}{l}\text { Immune compromised-MHC I } \\
\text { trafficking }\end{array}$ & retromer \\
\hline & Rab7 & GTPases & $\begin{array}{l}\text { Endosome maturation, } \\
\text { recruitment of retromer } \\
\text { implicated in Charcot marie- } \\
\text { Tooth type 2B }\end{array}$ & $\begin{array}{l}\text { Retrograde sorting is } \\
\text { impaired on mutation }\end{array}$ \\
\hline & Vps35 & Sorting factor & $\begin{array}{l}\text { Lower expression in brain } \\
\text { Alzheimer's disease }\end{array}$ & Retromer \\
\hline
\end{tabular}

\section{Conclusion}

With increasing recognition about the importance of retrograde transport in various crucial cellular processes and with the constant accumulation of information about the various factors participating in the transport from endosome -TGN, retrograde research has gained considerable interest in cell biology. The molecular mechanism about the existence of parallel pathways to TGN, sequence of events that occur during the traffic that drives transport in definite direction, tailor made regulatory and transport factors based on cargo makes the retrograde route complex and a carefully regulated pathway. Therefore we expect that advanced live cell microscopy will allow us to track single cargo traffic through intermediates, coupled with electron microscopy and proteomic approaches to map the function and the site of action of the newly discovered 
transport factors. Moreover the progressive events in sorting process coupled with endosome transformation/maturation need to be studied in finer detail and how are they linked? So does the role of cargo in recruitment of transport factors in sorting events ie how is the spacial molecular interaction co-ordinated between regulatory elements-cargo recognition complex-retrograde cargo. Further a matter of debate revolves around the question, where is the site of sorting in retrograde transport, is it early endosome or further downstream? Studies show that early endosome is the site but involvement of Rab7 for recruitment of sorting factors creates the confusion as Rab7 localises in late endocytic compartments. Elucidating the molecular events at progressive time points, dissecting the retrograde intermediate stations at nascent stages will help us built better models which will enable us to know the wholesome picture of the retrograde process. Study of retrograde trafficking not only is a challenging process in molecular biology as basic research but can open doors for therapeutic use as well. I conclude with promise that this field will continue to garner great deal of interest in future.

\section{References}

[1] S.D. Conner, S.L. Schmid, Regulated portals of entry into the cell, Nature 422, 2003, 37-44.

[2] S. Mayor and R.E. Pagano, Pathways of clathrin-independent endocytosis, Nat Rev Mol cell Biol., 8, $2007,613-612$.

[3] F.R. Maxfield ,T.E. Mcgraw, Endocytic recycling, Nat Rev. Mol. Cell Biol. , 5, 2004, 121-132.

[4] N.K. Gonatas, A Steiber, SU Kim, DI Graham, S Avrameas, Internalisation of neuronal plasma membrane ricin receptors into the Golgi apparatus, Exp. cell Res., 94, 1975, 426-431

[5] S Olsnes, A Pihl, Ricin - a potent inhibitor of protein synthesis, FEBS Letts,20, 1972, 327-329

[6] D Lombardi, T Soldati, M.A .Reiderer, Y Goda, M Zerial, S.R. Pfeffer, Rab 9 functions in transport between late endosome and trans Golgi network, EMBO J.,12,93,677-682

[7] W.M. Rohn, Y Rouille, S Waguri, B Roflack, Bi-directional trafficking between trans-Golgi network and the endosomal/lysosomal system, J Cell Sci., 113, 2000, 2093-2101

[8] M.N. Seaman, E.G. Marcusson, J.L. Cereghino, S.D. Emr, Endosome to Golgi retrieval of the vacuolar protein sorting receptor Vps 10p,requires the function of VPS29,VPS30,VPS35 gene products, J cell Biol., 137,1992, 79-92.

[9] M.N. Seaman, J.M. McCaffery, S.D. Emr, A membrane coat complex essential for endosome-to -Golgi retrograde transport in yeast, J Cell Biol., 142, 1998, 665-681.

[10] M.N. Seaman, Recycle your receptors with retromer, Trends Cell Biol., 15, 2005, 68-75

[11] C.R. Haft, et al, Human orthologs of yeast vacuolar protein sorting proteins Vps 26,30 and 35 : assembly into multimeric complexes, Mol. Biol. Cell, 11, 2005, 4105-4116

[12] J.H. Bonifacino, J.H. Hurley, Retromer, Curr. Opin. Cell .Biol., 20, 2008, 427-436.

[13] E Diaz, SR Pfeffer, TIP 47: a cargo selection device for mannpse-6-phosphate receptor, Cell 93, 1998, 433-443.

[14] A Saint-Pol, B Yelamos, M Amessou, I Mills, M Dugast, D Tenza, P Schu, C Antony, HT Macmahon, C Lamaze,L Johannes, Clathrin adaptor epsin $\mathrm{R}$ is required for retrograde sorting on early endosomal membranes, Dev. Cell 6,2004,525-538.

[15] V Popoff, G.A. Mardones, D Tenza, R Rojas, C Lamaze, J Bonifacino, J Raposso, L Johannes, The retromer complex and clathrin define an early endosomal retrograde exit site, J Cell Sci., 120, 2007,2022-2031.

[16] E. Sztul, V. Lupashin, Role of tethering factors in secretory membrane traffic, Am. J. Physiol. Cell. Physiol., 290, 2006, C11-C26

[17] J.S. Bonifacino and R Rojas, Retrograde transport from endosome to trans-Golgi network, Nat. Rev. Mol. Cell Biol., 7, 2006, 568579

[18] G.R. Medigeshi, P Shu, Characterisation of in vitro retrograde transport of MPR46, Traffic, 4, 2003, 802-811

[19] N.J. Bryan, R Govers, D.E. James, Regulated transport of the glucose transporter GLUT4, Nat. Rev. Mol. Cell Biol., 3, 2002, 267277

[20] J.S. Bogan, K.V. Kandror, Biogenesis and regulation of insulin responsive vesicles containing GLUT4, Curr. Opin. Cell Biol., 22, 2010, 506-512

[21] M.J. Petris, J.S.Mercer, The Menkes protein cycles via the plasma membrane both in basal and elevated extra cellular copper using a C-terminal di-leucine endocytic signal, Hum. Mol. Genet., 8, 2107-2115

[22] X Wang, D Ma, J Oja-Kesky, D Pei, Co-recycling of MT1MMP and MT3MMP through the trans-Golgi network, Identification of DKV582 as a recycling signal, J. Biol. Chem., 279, 9331-9336.

[23] S Eaton, Retromer retrieves wntless, Dev. Cell, 14, 2008, 4-6.

[24] D Moron, G Dadaglio, C Leclerc, New tools for antigen delivery to the MHC class I pathway, Trends Immunol., 25,2004, 92-97

[25] B Vingert, O Adotevi, M Amessou, S Jung, P Shrikant, A Sapoznikov, D Patin, L Freyburger, W.H. Fridman, L Johannes, The Shiga toxin B-subunit targets antigen in vivo to dendritic cells and elicits anti tumour immunity, Eur. J. Immunol., 36, 2006, 11241135 .

[26] A Muhammed, I Flores, H Zang, R Yu, A Staniszewski, E Planel, H Herman, L Ho, R Kreber, LS Honig, B Ganetzky, K Duff, O Arancio, S.A. Small, Retromer defficiency observed in Alzheimer's disease causes hippocampal dysfunction, neurodegeneration, and Abeta accumulation. Proc. Natl. Acad Sc USA, 2008, 105, 7327-7332.

[27] S. Lopez Verges, G. Camus, G Blot, R Beauvoir, R Benarous, C Berlioz-Torrent, Tail interacting protein TIP47 is a connector between Gag and Env and is required for Env incorporation into HIV virions, Proc. Natl. Acad. Sc. USA,103, 2006, 14947-14952 